\title{
Paradoxical effects of essential fatty acid supplementation on lipid profiles and sweat electrolytes in cystic fibrosis
}

\author{
BY JOHN A. DODGE*, JACQUELINE M. CUSTANCE, MARY C. GOODCHILD, \\ SHEENA C. LAING AND MERLE VAUGHAN \\ Department of Child Health, University of Wales College of Medicine, Heath Park, \\ Cardiff CF4 $4 X N$
}

(Received 21 September 1989 - Accepted 10 October 1989)

\begin{abstract}
Supplements of evening primrose oil (Oenothera biennis), which contains at least $72 \%$ linoleic $(18: 2 n$ 6) and $7 \% \gamma$-linolenic (18:3 $n$-6) acids (expressed as \% fatty acid methyl esters) were given to sixteen cystic fibrosis patients for a period of 12 months. Clinical observations showed no significant changes in patients' weights or respiratory function throughout. Linoleic acid levels in plasma and erythrocyte membranes increased significantly during the first 6 months but this increase was not sustained at its initial level. After supplementation was discontinued reversion to baseline (low) levels occurred within 4 months. Levels of plasma prostaglandins (PG) and urinary PG metabolites varied among individuals over a wide range, and urinary $\mathbf{P G F}_{2 \pi}$ metabolites fell during the supplementation. There was a significant fall in sweat sodium concentrations after 6 weeks of supplementation, but sweat chloride was unchanged. It is not known whether the effect of essential fatty acids on sweat $\mathrm{Na}^{+}$reflects changes in cell membrane conformation or if there is a direct effect on $\mathrm{Na}^{+}$pump activity.
\end{abstract}

Cystic fibrosis: Essential fatty acids: Sweat electrolytes

Deficiency of the essential fatty acid (EFA) linoleic acid, 18:2n-6, has been widely reported in cystic fibrosis (CF), particularly but not exclusively when there is impairment of pancreatic function (Hubbard et al. 1977; Lloyd-Still et al. 1981). Evidence that there is an increased turnover of certain fatty acids in CF has been provided by Rogiers et al. (1984). The metabolites of linoleic acid (Fig. 1) are prostaglandin (PG) precursors, and urinary metabolites of $\mathrm{PGE}_{2}$ are increased in patients with $\mathrm{CF}$ and in heterozygotes (Burns \& Dodge, 1982), although EFA deficiency is usually associated with reduction of PGE synthesis and a corresponding decrease in the excretion of its metabolites (Friedman et al. 1980). Thus, there appears to be increased metabolism of, and perhaps increased requirement for, EFA in CF. Further evidence for an increased turnover of the linoleic acid derivative arachidonic acid $(20: 4 n-6)$ has been provided by Carlstedt-Duke et al. (1986) who showed that the normal inhibition of arachidonic acid release from lymphocytes by dexamethasone is not seen in CF. They postulated that many of the clinical and biochemical features of CF can be explained on this basis. The recent identification of the major CF mutation and its corresponding protein implicates an abnormal binding site for ATP as the primary defect (Riordan et al. 1989). Intracellular energy cycles are likely to be disturbed, and secondary effects on fatty acid metabolism might be expected.

For these and other reasons, various authors have attempted clinical trials of EFA supplements in CF. One of the earliest reports was of a single patient studied by Elliott \& Robinson (1975) to whom Intralipid ${ }^{\mathbb{B}}$, an intravenous emulsion of soya-bean oil, was given by regular infusion. Clinical benefit was reported, and perhaps most interestingly it was

\footnotetext{
* Present address: Department of Child Health, Queen's University of Belfast, Institute of Clinical Science, Grosvenor Road, Belfast BT12 6BJ.
} 
$18: 2 n-6$ Linoleic acid

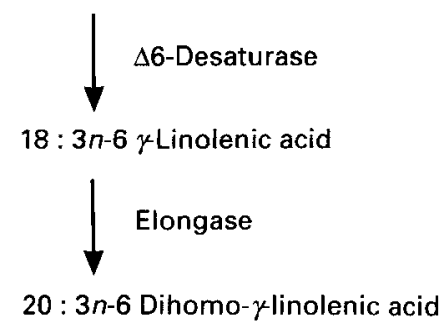
Prostaglandins $\mathrm{E}_{1}$, $\mathrm{F}_{1 \alpha}$ etc. and leukotrienes

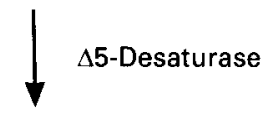

Prostaglandins $\mathrm{E}_{2}$, $F_{2 \alpha}$ etc. and leukotrienes

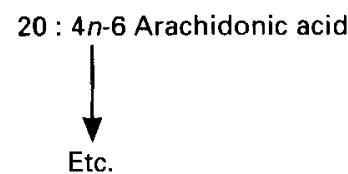

Fig. 1. The metabolic pathway of linoleic acid.

claimed that sweat electrolyte concentrations were reduced. Elevated sweat electrolytes are a characteristic feature of CF. Although another trial of Intralipid produced no fall in sweat chlorides (Kussavsky et al. 1983) others also found that in some patients sweat sodium does fall after EFA supplementation (Rosenlund et al. 1977). Oral supplements of maize oil (Rosenlund et al. 1977), safflower oil (Mischler et al. 1986; Lloyd-Still et al. 1979), and linoleic acid monoacylglycerol (Christophe et al. 1985) have also been used and again the results conflict. Some have claimed clinical benefit without any change in the EFA status (Chase et al. 1979) while others have been able to raise the blood levels of EFA with corresponding increases in the urinary excretion of $\mathrm{PGE}_{2}$ metabolites (Mischler et al. 1986).

In the present study we observed the effects of oral supplementation with oil of evening primrose (Oenothera biennis), which is rich in linoleic $(18: 2 n-6)$ and $\gamma$-linolenic acids $(18: 3 n-6)$, on the clinical state, sweat electrolytes and fatty acid profiles of a group of children with $\mathrm{CF}$.

\section{SUBJECTS AND METHODS}

Sixteen patients with CF were enrolled in the study, nine female and seven male. Informed consent was obtained from patients, parents, or both. Ages ranged from 3.4 to 23.0 (mean $9 \cdot 2$ ) years. Each subject received oil of evening primrose by mouth as a dietary supplement for a period of 12 months in a daily dose of $1 \mathrm{~g} / \mathrm{kg}$ body-weight to a maximum of $25 \mathrm{~g}$. The oil contains at least $72 \%$ linoleic acid and $7 \% \gamma$-linolenic acid expressed as a percentage of total fatty acid methyl esters (Table 1). During the first 3 months the oil was given in standard commercial capsules (Efamol ${ }^{\circledR}$ ) which also contain vitamin $\mathrm{E}$, but because of patient difficulty with taking large numbers of capsules the preparation was changed to liquid oil (prepared in individual dark brown $10 \mathrm{ml}$ bottles) supplied by the same manufacturer. The oil did not contain added vitamin E, which was therefore given as an additional supplement ( $200 \mathrm{mg}$ daily) from 6 months on, and continued after oil supplements ceased.

The patients attended a special research clinic where baseline anthropometric and biochemical measurements were made $(a)$ before supplementation began and the same 
Table 1. Composition of evening primrose (Oenothera biennis) oil (mol/mol total fatty acid)

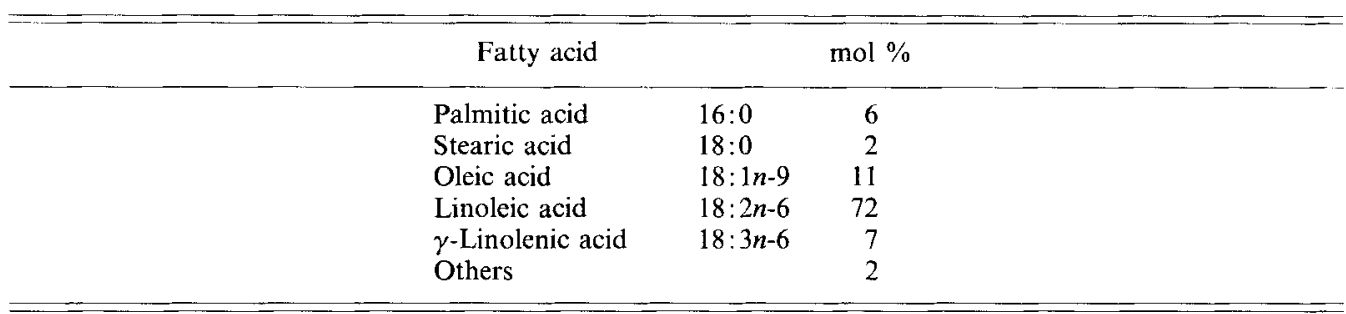

variables were monitored after $(b) 6$ weeks, $(c) 6$ months, $(d) 12$ months and $(e) 16$ months, the last measurements being made 4 months after the supplement had been discontinued. Height, weight, triceps skinfold thickness and simple lung function tests were measured using standard equipment. Sweating of the forearm was stimulated by the standard pilocarpine iontophoresis method of Gibson \& Cooke (1959), sweat was collected into weighed $\mathrm{Na}^{+}$-free gauze pads, and the $\mathrm{Na}^{+}$and $\mathrm{Cl}^{-}$contents were measured by flame photometry and titration respectively. Plasma cholesterol, triacylglycerols, zinc, vitamin $\mathrm{E}$ and $24 \mathrm{~h}$ urinary creatinine were measured in the routine clinical laboratories of the University Hospital of Wales. Blood samples $(5 \mathrm{ml})$ for fatty acid analysis were collected in heparinized tubes and centrifuged at $2000 \mathrm{rev} . / \mathrm{min}$ for $10 \mathrm{~min}$ at $4^{\circ}$ within $10 \mathrm{~min}$ of venepuncture. The erythrocytes were thrice washed with saline $(9 \mathrm{~g}$ sodium chloride $/ 1)$ and were again centrifuged between washings. Erythrocyte and plasma lipids were extracted using the Folch et al. (1957) extraction method, with chloroform-methanol $(2: 1, \mathrm{v} / \mathrm{v})$ with $0.01 \%$ butylated hydroxytoluene (Lloyd-Still et al. 1981). Plasma lipids (1 ml) were separated into individual classes (free fatty acids, cholesteryl esters, triacylglycerols, phospholipids) by thin layer chromatography (TLC) using silica gel plates heated for $1 \mathrm{~h}$ at $110^{\circ}$ and light petroleum (b.p. $40-60^{\circ}$ ), diethyl ether, and glacial acetic acid $(90: 10: 1$, by vol.). Plates were run twice for $30 \mathrm{~min}$ in the solvent system, dried, and spots were visualized using rhodamine and examined under u.v. light. The erythrocyte phospholipids were separated using TLC and chloroform-methanol-water-ammonium hydroxide (60:35:2:2 by vol.) Plates were run for $50 \mathrm{~min}$, using standards of phosphatidyl choline, phosphatidyl serine, phosphatidyl inositol, phosphatidyl ethanolamine and sphingomyelin. Extracted lipids were methylated using methanol and sulphuric acid. The resulting fatty acid methyl esters were extracted with light petroleum (b.p. $40-60^{\circ}$ ) then analysed using a Pye 204 gas-liquid chromatograph with SCOT FFAP capillary column, inlet splitter and flame ionization detector with helium as a carrier gas. Blood samples for PG analysis were centrifuged within $10 \mathrm{~min}$ of venepuncture before the plasma was extracted and submitted to radioimmunoassay as previously described by Dodge et al. (1981). Collections (24 h) of urine for PG metabolites (PGM) were extracted with chloroform, separated on silicic acid columns using toluene-acetate-methanol systems (Haning et al. 1977) and assayed using antisera provided by Miles-Yeda Laboratories (Israel). Coefficients of variation for the PG assays were $4 \cdot 2,6 \cdot 8,8 \cdot 1$ and $12 \cdot 1 \%$ for $\mathrm{PGE}_{2}, \mathrm{PGF}_{2 \alpha}, \mathrm{PGE}_{2} \mathrm{M}$ and $\mathrm{PGF}_{2 \alpha} \mathrm{M}$ respectively. Controls for the plasma prostaglandins and urine metabolites $(n 15)$ were healthy young adults, and plasma values were in the same range as those previously found in healthy children (Dodge et al. 1981). Control values for total plasma and erythrocyte fatty acids were obtained from healthy children $(n 30)$. 
Table 2. Anthropometric measurements: height, weight and triceps skinfold (percentage of normal values appropriate for age and sex) for subjects with cystic fibrosis receiving an essential fatty acid supplement as evening primrose (Oenothera biennis) oil for 12 months

(Mean values, range and standard deviations)

\begin{tabular}{|c|c|c|c|c|c|c|}
\hline \multicolumn{2}{|c|}{ Stage of treatment ... } & \multirow{2}{*}{$\begin{array}{l}\text { Baseline } \\
94 \cdot 46 \\
86 \cdot 8 \cdot-103 \cdot 6 \\
4 \cdot 4\end{array}$} & \multirow{2}{*}{$\begin{array}{l}6 \text { weeks } \\
\begin{array}{l}94 \cdot 51 \\
87 \cdot 71-104 \cdot 44 \\
4 \cdot 66\end{array}\end{array}$} & \multirow{2}{*}{$\begin{array}{l}6 \text { months } \\
94 \cdot 63 \\
87 \cdot 7-104 \cdot 23 \\
4 \cdot 54\end{array}$} & \multirow{2}{*}{$\begin{array}{l}12 \text { months } \\
94 \cdot 69 \\
89 \cdot 08-105 \cdot 15 \\
4.45\end{array}$} & \multirow{2}{*}{$\begin{array}{l}16 \text { months } \\
94.67 \\
89 \cdot 22-103.60 \\
4.44\end{array}$} \\
\hline Height & $\begin{array}{l}\text { Mean } \\
\text { Range } \\
\text { SD }\end{array}$ & & & & & \\
\hline Body-wt & $\begin{array}{l}\text { Mean } \\
\text { Range } \\
\text { SD }\end{array}$ & $\begin{array}{l}78 \cdot 6 \\
53 \cdot 3-101 \cdot 6 \\
12 \cdot 1\end{array}$ & $\begin{array}{l}79 \cdot 68 \\
58 \cdot 61-102 \cdot 89 \\
12 \cdot 15\end{array}$ & $\begin{array}{l}78 \cdot 94 \\
59 \cdot 20-103-00 \\
11 \cdot 66\end{array}$ & $\begin{array}{l}77 \cdot 93 \\
55 \cdot 61-104 \cdot 04 \\
13 \cdot 08\end{array}$ & $\begin{array}{l}76.99 \\
56 \cdot 07-100 \cdot 90 \\
12 \cdot 61\end{array}$ \\
\hline Skinfold & $\begin{array}{l}\text { Mean } \\
\text { Range } \\
\text { SD } \\
n\end{array}$ & $\begin{array}{l}74 \cdot 0 \\
40 \cdot 0-102 \cdot 2 \\
17 \cdot 4 \\
16\end{array}$ & $\begin{array}{l}71 \cdot 70 \\
47 \cdot 5 \cdot 90 \cdot 24 \\
13 \cdot 44 \\
15\end{array}$ & $\begin{array}{l}70 \cdot 42 \\
43 \cdot 9-108 \cdot 16 \\
15 \cdot 33 \\
16\end{array}$ & $\begin{array}{l}75 \cdot 47 \\
52 \cdot 3-101 \cdot 23 \\
14 \cdot 42 \\
16\end{array}$ & $\begin{array}{l}64 \cdot 94 \\
42 \cdot 85-109 \cdot 52 \\
18 \cdot 94 \\
15\end{array}$ \\
\hline
\end{tabular}

Table 3. Lung-function tests (percentage of standards-for-height) for subjects with cystic fibrosis receiving an essential fatty acid supplement as evening primrose (Oenothera biennis) oil for 12 months

(Mean values and standard deviations)

\begin{tabular}{lllllll}
\hline \hline \multicolumn{2}{r}{ Stage of treatment $\ldots$} & Baseline & 6 weeks & 6 months & 12 months & 16 months \\
\hline FEV & Mean & $60 \cdot 1$ & $67 \cdot 4$ & $59 \cdot 3$ & $61 \cdot 6$ & $60 \cdot 2$ \\
& Range & $26 \cdot 7-118 \cdot 5$ & $25 \cdot 0-113 \cdot 6$ & $16 \cdot 2-116 \cdot 7$ & $27 \cdot 3-112 \cdot 6$ & $14 \cdot 0-105 \cdot 8$ \\
& SD & $23 \cdot 7$ & $16 \cdot 2$ & $26 \cdot 7$ & $21 \cdot 2$ & $25 \cdot 0$ \\
FVC & Mean & $72 \cdot 8$ & $79 \cdot 9$ & $70 \cdot 9$ & $75 \cdot 0$ & $72 \cdot 2$ \\
& Range & $46 \cdot 4-127 \cdot 4$ & $41 \cdot 3-133 \cdot 7$ & $37 \cdot 9-122 \cdot 0$ & $42 \cdot 9 \cdot 133 \cdot 4$ & $20 \cdot 5-119 \cdot 5$ \\
& SD & $23 \cdot 8$ & $22 \cdot 7$ & $29 \cdot 2$ & $24 \cdot 0$ & $26 \cdot 8$ \\
PFR & Mean & $78 \cdot 8$ & $87 \cdot 6$ & $74 \cdot 6$ & $72 \cdot 6$ & $73 \cdot 2$ \\
& Range & $50 \cdot 0-120 \cdot 8$ & $48 \cdot 4-122 \cdot 9$ & $36 \cdot 1-124 \cdot 1$ & $35 \cdot 1$ & $46 \cdot 0-126 \cdot 0$ \\
& SD & $24 \cdot 4$ & $26 \cdot 1$ & $26 \cdot 4$ & $26 \cdot 4$ & $24 \cdot 7$ \\
& $n$ & 16 & 14 & 16 & 12 & 15 \\
\hline
\end{tabular}

$\mathrm{FEV}_{1}$, forced expiratory volume at $1 \mathrm{~s}$ (litres); FVC, forced vital capacity (litres); PFR, peak expiratory flowrate (litres/min)

\section{Statistical analysis}

Results were submitted to an analysis of variance for repeated measures using the P2V program in the BMDP package (Dixon et al. 1983). If a significant $F$ ratio test result was obtained for the comparison of the means at different times, Dunnett's test was used to compare each mean with the mean at baseline (Winer, 1962). Some variables were transformed by taking logarithms before analysis of variance.

\section{RESULTS}

No significant changes in height, weight, triceps skinfold thickness or lung function test results (expressed as percentages of mean normal values appropriate for age and sex of the subjects) occurred during the study (Tables 2 and 3 ). 


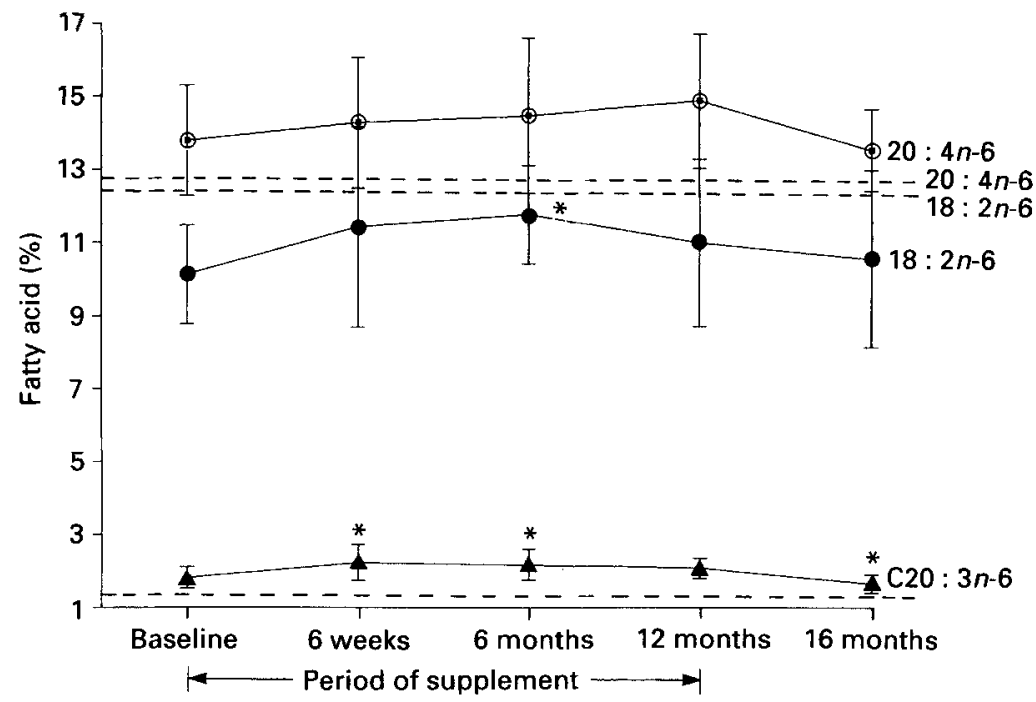

Fig. 2. Total erythrocyte fatty acids of patients with cystic fibrosis receiving an essential fatty acid (EFA) supplement as evening primrose (Oenothera biennis) oil. (--), Mean values in healthy children. Points are means, and standard deviations are represented by vertical bars. For details of supplement, sce Table 1 and p. 260 . * $P<0.05$. Comparisons are between baseline and 6 weeks $/ 6$ months $/ 12$ months, and between 12 and 16 months.

Changes in fatty acid composition of erythrocytes are shown in Fig. 2. It will be seen that linoleic $(18: 2 n-6)$ acid levels increased significantly during the first 6 months, although never reaching normal mean values, but that the increase was not sustained. After supplementation was stopped, reversion to baseline (low) levels occurred within 4 months. A similar change occurred in the case of the EFA dihomo- $\gamma$-linolenic acid $(20: 3 n-6)$, but in this case the rise was maintained until supplementation ceased at 12 months. Baseline values for $20: 3 n-6$ were already increased above those of normal child controls and giving $18: 2 n-6$ and $18: 3 n-6$, which are both present in evening primrose oil, had the expected effect of further elevation. This was also seen in the case of the important structural fatty acid 20:4n-6 (arachidonic), which started from a high level and increased until 12 months despite the fall in the level of its major precursor, $18: 2 n-6$, but reflecting the sustained rise in its immediate precursor, 20:3n-6. Statistically significant $(P<0 \cdot 05)$ increases in 18:2n6 and $20: 3 n-6$ in erythrocyte phospholipids at 6 and 12 months were noted in the phosphatidyl choline component only, but there was no significant increase in $20: 4 n-6$. No significant changes in EFA were seen in the phosphatidyl ethanolamine fraction. Detailed fatty acid analyses of these phospholipid fractions are available on file; other phospholipids were present in very small amounts.

Total plasma fatty acids showed changes similar to those in the erythrocyte, also reverting quickly to baseline levels when supplementation was stopped (Fig. 3). Similar changes in the relative proportions of fatty acids during supplementation were also seen in the individual components of plasma lipids, i.e. cholesteryl esters, triacylglycerols, phospholipids and free fatty acids, with varying degrees of statistical significance. Details of these results have been omitted from the present report because they added nothing of importance to the observed changes in total plasma fatty acids, except that a continuing elevated level of EFA in the triacylglycerol fraction at a time when total erythrocyte and plasma $18: 2 n-6$ was falling (6-12 months) is an indirect confirmation of continuing patient compliance in the supplement trial (Table 4). 


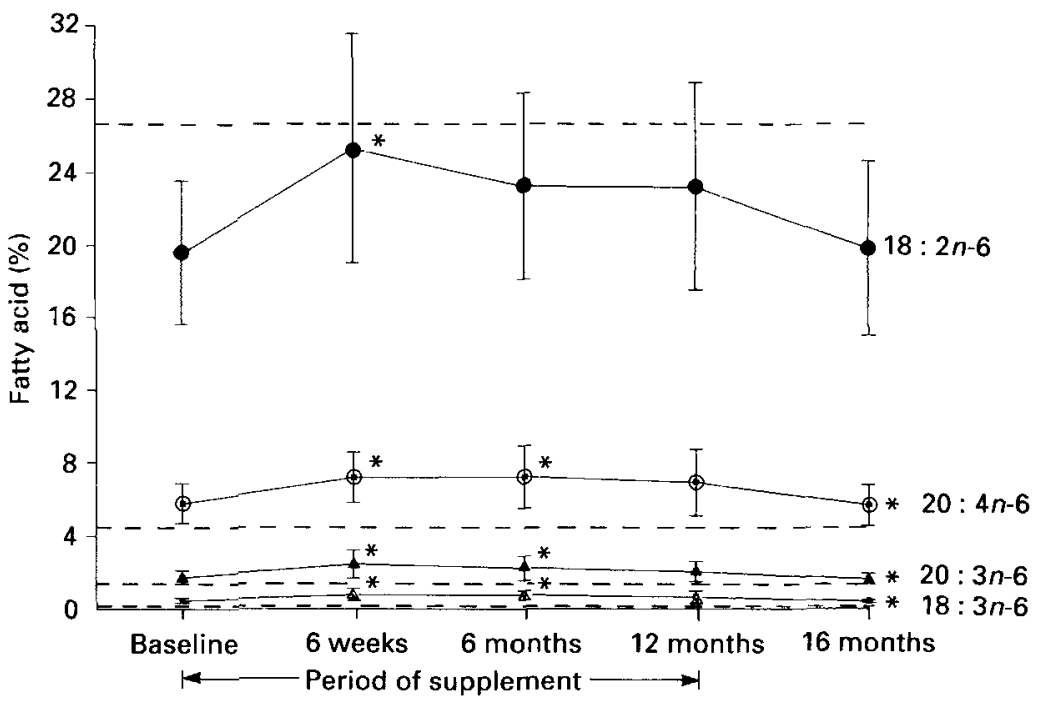

Fig. 3. Total plasma fatty acids of patients with cystic fibrosis receiving an essential fatty acid (EFA) supplement as evening primrose (Oenothera biennis) oil. (--), Mean values in healthy children. Points are means, and standard deviations are represented by vertical bars. For details of supplement, see Table 1 and p. 260 . $^{*} P<0 \cdot 05$. Comparisons are between baseline and 6 weeks/ 6 months/ 12 months, and between 12 and 16 months.

Table 4. Plasma triacylglycerols: selected fatty acids (\%)

(Mean values and standard deviations)

\begin{tabular}{|c|c|c|c|c|c|c|c|c|c|c|}
\hline \multirow{2}{*}{$\begin{array}{l}\text { Stage of } \\
\text { treatment ... } \\
\text { Fatty acid }\end{array}$} & \multicolumn{2}{|c|}{ Baseline } & \multicolumn{2}{|c|}{6 weeks } & \multicolumn{2}{|c|}{6 months } & \multicolumn{2}{|c|}{12 months } & \multicolumn{2}{|c|}{16 months } \\
\hline & Mean & $\mathrm{SD}$ & Mean & SD & Mean & so & Mean & SD & Mean & so \\
\hline $6: \ln -3$ & $7 \cdot 24$ & 1.47 & $6 \cdot 13$ & 1.47 & $5 \cdot 97$ & $1 \cdot 32$ & 6.02 & $1 \cdot 33$ & $5 \cdot 94$ & $1 \cdot 10$ \\
\hline $18: 2 n-6$ & $9 \cdot 50$ & $5 \cdot 53$ & $13 \cdot 90$ & 6.45 & $13 \cdot 49$ & $3 \cdot 27$ & $15 \cdot 54^{*}$ & $4 \cdot 8$ & $11.68^{*}$ & 4.95 \\
\hline $18: 3 n-6$ & $0-30$ & 0.11 & 0.49 & 0.29 & 0.60 & 0.24 & 0.59 & 0.41 & 0.39 & $0 \cdot 27$ \\
\hline $20: 4 n-6$ & 0.96 & 0.41 & $1 \cdot 23$ & 0.62 & $1.72 *$ & 0.74 & $1 \cdot 85^{*}$ & 0.83 & $1 \cdot 11^{*}$ & 0.41 \\
\hline
\end{tabular}

* Mean values were significantly different from baseline levels (or between 12 and 16 months) $(P<0.05)$.

PG levels in plasma and urine PGM varied among individuals over a wide range. Plasma $\mathrm{PGE}_{2}$ and $\mathrm{PGF}_{2 \alpha}$ levels both fell during supplementation (without reaching statistical significance) and reverted to baseline levels later (Fig. 4 and Table 5). A consistent fall in urine $\mathrm{PGF}_{2} \mathrm{M}$ was seen, but a less consistent upward trend was seen in the case of $\mathrm{PGE}_{2} \mathrm{M}$. The excretion of PGM related to urinary creatinine excretion is shown diagrammatically in Fig. 5. However, some of the samples for $\mathrm{PGE}_{2} \mathrm{M}$ analysis were stored under varying conditions at the 12-month stage so that the apparent secondary fall in $\mathrm{PGE}_{2} \mathrm{M}$ may not be real.

Urine $24 \mathrm{~h}$ creatinine excretion rose significantly $(P<0.05)$ during the first 6 months and then fell, returning to baseline values when supplementation stopped. Plasma creatinine fell during the first 6 months although this did not quite reach statistical significance. Thus, plasma creatinine was falling at a time when its urinary excretion was rising. Plasma cholesterol and triacylglycerol levels both fell during the first 6 months of EFA 

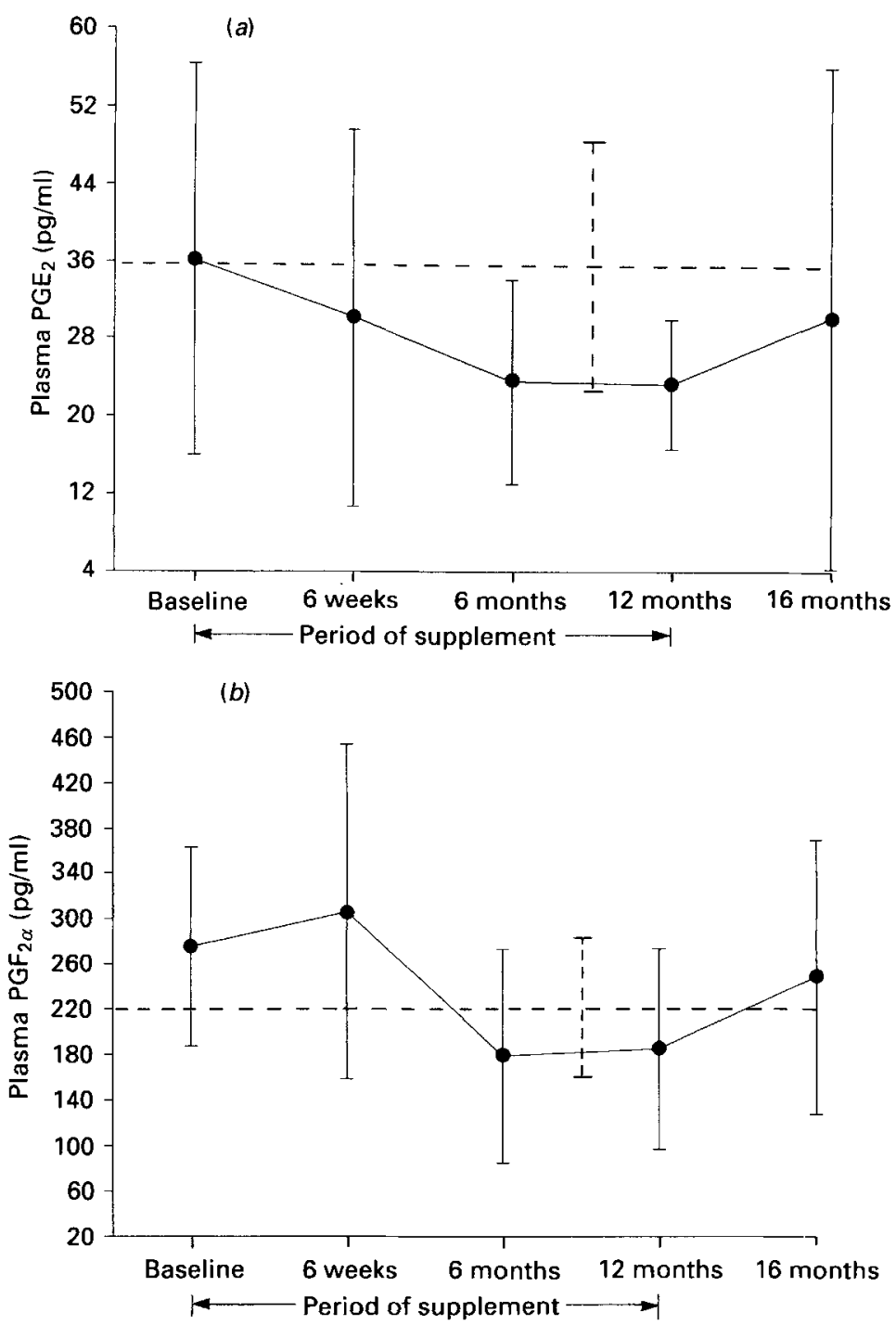

Fig. 4. (a) Plasma prostaglandin $\mathrm{E}_{2}\left(\mathrm{PGE}_{2}\right)$ and $(b)$ prostaglandin $\mathrm{F}_{2 \alpha}$ (PGF $\mathrm{PG}_{2 \alpha}$ of patients with cystic fibrosis receiving an essential fatty acid (EFA) supplement as evening primrose (Oenothera biennis) oil. Points are means, and standard deviations are represented by vertical bars. (--), Mean values in healthy children. For details of supplement, see Table I and p. 260.

supplementation. In the case of cholesterol, mean levels were almost back to baseline at 12 months. The fall in triacylglycerol reached statistical significance at 6 months and levels remained low up to 16 months. No significant changes occurred in plasma zinc levels, but serum vitamin $E$ concentrations increased from a low baseline value and remained elevated at 16 months. The relatively low values observed at 6 months reflect the change-over from capsules containing vitamin $\mathrm{E}$ to the oil itself, before specific vitamin $\mathrm{E}$ supplements were given (Table 5).

Sweat electrolyte measurement showed no change in the $\mathrm{Cl}^{-}$concentration (Fig. 6), but a significant fall in $\mathrm{Na}^{+}$after 6 weeks supplementation, following an initial rise (Fig. 7). 


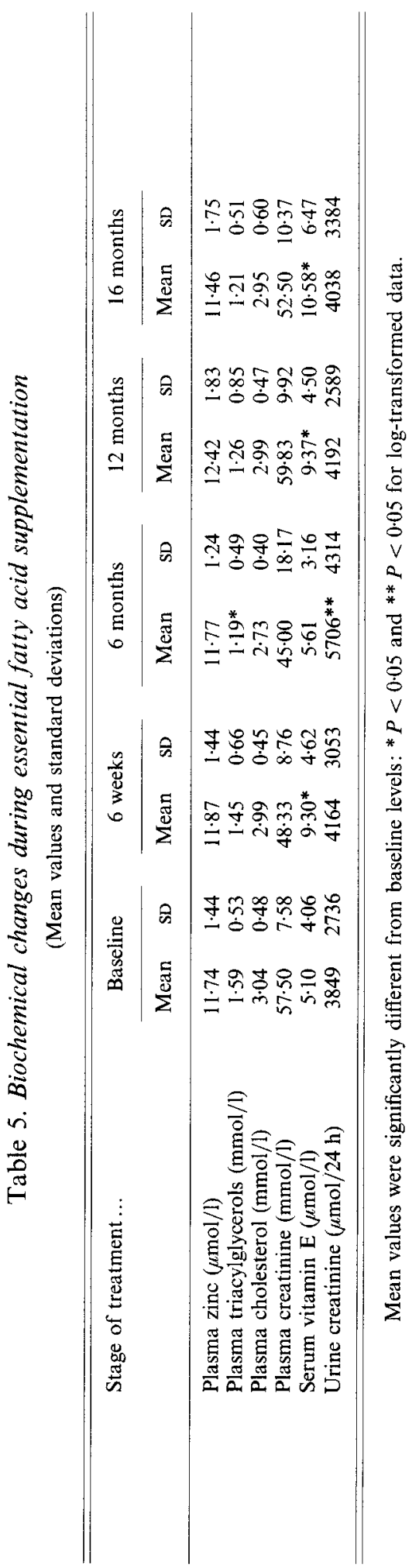




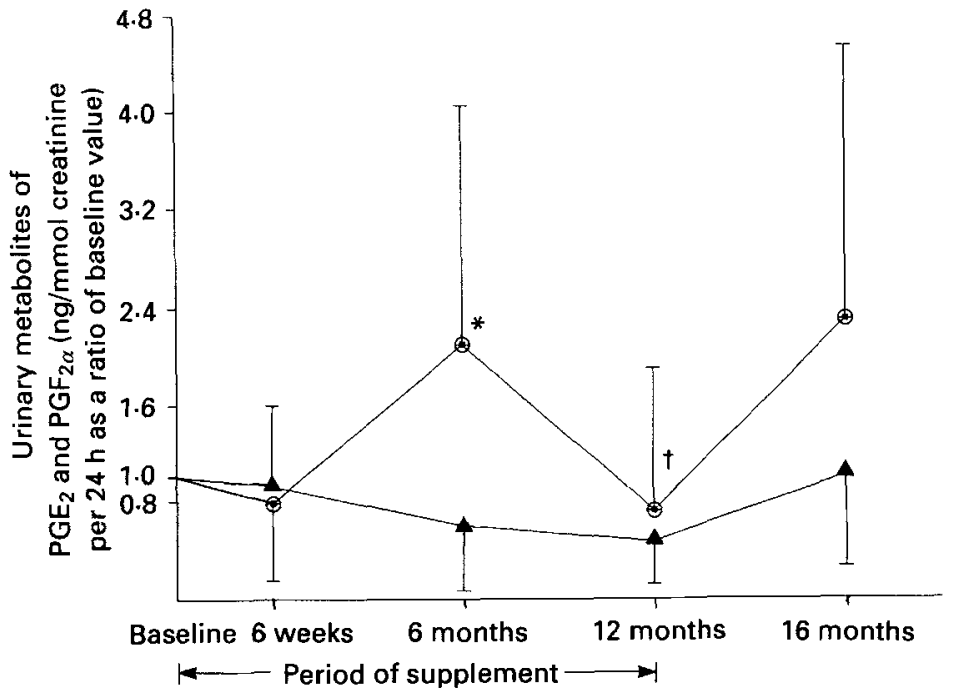

Fig. 5. Urinary metabolites of prostaglandins $\mathrm{E}_{2}\left(\mathrm{PGE}_{2}\right)$ and $\mathrm{F}_{2 \alpha}\left(\mathrm{PGF}_{2 \alpha}\right)(\mathrm{ng} / \mathrm{mmol}$ creatinine per $24 \mathrm{~h}$ as a ratio of baseline value) in patients with cystic fibrosis receiving an essential fatty acid (EFA) supplement as evening primrose (Oenothera biennis) oil. Points are means, and standard deviations are represented by vertical bars. For details of supplement see Table 1 and p. $260 .{ }^{*} P<0.05$ on log-transformed data. Comparison with baseline. + Indicates a value that may be inaccurate (see text).

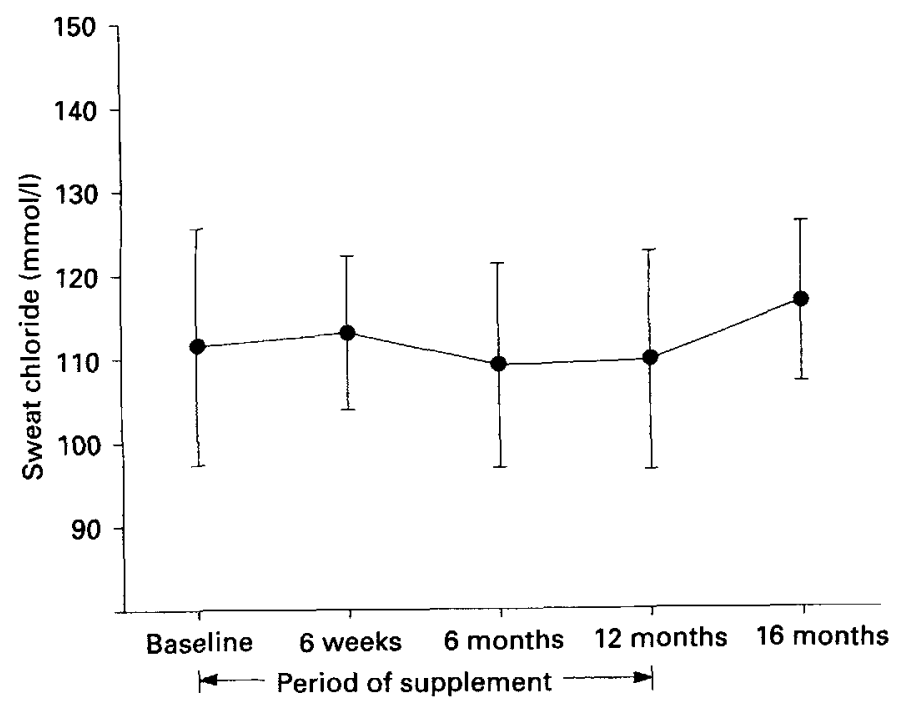

Fig. 6. Iontophoresis sweat chloride levels of patients with cystic fibrosis receiving an essential fatty acid (EFA) supplement as evening primrose (Oenothera biennis) oil. Points are means, and standard deviations are represented by vertical bars. For details of supplement see Table 1 and p. 260. 


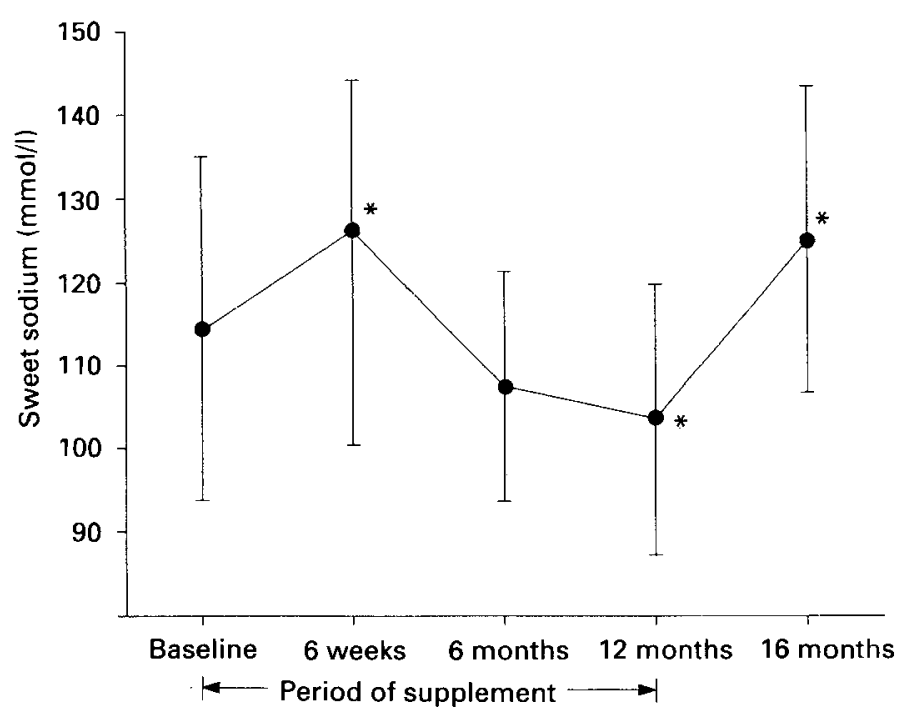

Fig. 7. Iontophoresis sweat sodium levels of patients with cystic fibrosis receiving an essential fatty acid (EFA) supplement as evening primrose (Oenothera biennis) oil. Points are means, and standard deviations are represented by vertical bars. For details of supplement, see Table I and p. $260 .{ }^{*} P<0 \cdot 05$. Comparisons are between baseline and 6 weeks $/ 6$ months/ 12 months, and between 12 and 16 months.

\section{DISCUSSION}

Among the many biochemical changes observed in these patients during dietary supplementation with evening primrose oil, three are of particular interest and may shed some light on the underlying metabolic abnormality in CF. These are the failure to maintain levels of linoleic acid initially achieved despite continuation of the EFA supplement, the elevated levels of linoleic acid metabolites seen throughout the study, and the effects of EFA on sweat electrolyte concentrations.

It is clear from Figs 2 and 3 that the plasma linoleic acid level responds well to oral EFA supplementation at 6 weeks, and that at 6 weeks and 6 months this increased uptake of linoleic acid has been reflected in an increased incorporation into erythrocyte membranes. However, by 12 months the linoleic acid levels of both plasma and erythrocytes are reverting back towards baseline values, although the oral supplements were continuing. One possible explanation for failure to sustain the improvement in linoleic acid status (which only achieved normal mean values at any stage in a minority of subjects) is that the supplementary linoleic acid may have been used as a general source of energy, in which case increasing the total energy intake might have avoided the secondary fall that occurred after initial improvement (Parsons et al. 1988). However, if inadequate total energy intake is the explanation, the substantial early rise in linoleic acid would not have been expected. It is nevertheless possible that the increase in available linoleic acid was directed to one of its important functions as a regulator of intracellular metabolism, particularly in ion channel control (McKenna et al. 1985). The distribution of absorbed linoleic acid is to body cells for storage as triacylglycerol, oxidation to energy, metabolism to its derivatives (Fig. 1) or incorporation in membrane phospholipids, whence it can be mobilized again, particularly from phosphatidyl inositol. It is of interest that inositol, when complexed with phosphate, plays a key role in the maintenance of intracellular ionic homeostasis (McPherson \& Dormer, 1987). We were unable, for practical reasons, to measure phosphatidyl inositol 
fatty acids in our patients because although phosphatidyl inositol has high metabolic activity and turnover it forms only a small fraction of total membrane phospholipids, but others have shown a unique relationship between phosphatidyl inositol and dietary fatty acids. In guinea-pig lung, phosphatidyl inositol concentrations of arachidonic acid decrease when there is dietary linoleic acid deficiency, and also decrease with linoleic acid excess (Senne \& Mathias, 1987). This suggests that linoleic acid may be the preferred fatty acid in phosphatidyl inositol, so that when available it replaces arachidonic acid, but if linoleic acid is not available then arachidonic acid will fall as it is used up. By contrast, in other classes of phospholipid, arachidonic acid tends to be conserved even when there is marked linoleic acid deficiency (Lefkowith et al. 1986). Previous studies in our laboratory on platelets (Burns \& Dodge, 1982) and elsewhere on erythrocytes (R. T. Holman, personal communication) have found low linoleic acid levels not only in CF homozygotes but also in their parents, who have no impairment of linoleic acid absorption. This is consistent with an intrinsic abnormality of EFA metabolism in CF, resulting in enhanced turnover of linoleic acid (Rogiers et al. 1984), perhaps through the phosphatidyl inositol fraction, which is also present in heterozygotes.

There is no evidence of a defect in $\Delta 5$ - or $\Delta 6$-desaturase in $C F$ from this or other studies. In fact, plasma arachidonic acid levels as well as those of intermediate linoleic acid derivatives were normal or slightly elevated at the start of the EFA supplementation, and were increased and well maintained throughout. In the case of erythrocyte arachidonic acid and 20:3n-6 there was no secondary fall such as was seen in the case of linoleic acid, and the increases continued until EFA supplementation was stopped at 12 months, when the levels quickly reverted to pretreatment values (Fig. 2). Elevation of linoleic acid metabolites such as arachidonic acid has been seen before in CF (Lloyd-Still et al. 1981; Parsons et al. 1988) and indicates that it is the linoleic acid itself that is being actively utilized.

It is possible that the increased proportions of these linoleic acid derivatives in cell membranes might alter the permeability characteristics sufficiently to account for the consistent and significant decrease in stimulated sweat $\mathrm{Na}^{+}$concentrations that occurred during the study, but this would not in itself explain the initial elevation in sweat $\mathrm{Na}^{+}$ during the first 6 weeks (Fig. 7), although the transient increase in membrane linoleic acid levels might do so. Current opinion favours control of the transport of $\mathrm{Cl}^{-}$rather than $\mathrm{Na}^{+}$ as the site of the primary abnormality in $\mathrm{CF}$, but sweat $\mathrm{Cl}^{-}$concentrations were unaffected. Changes in membrane conformation might not only affect ion channels, but also the exposure or masking of receptors, and the activity of ion-exchange pumps. Some previous reports have claimed that EFA supplements reduce sweat $\mathrm{Na}^{+}$(Elliott \& Robinson, 1975; Rosenlund et al. 1977) while others have found no effect on $\mathrm{Cl}^{-}$concentrations (Lloyd-Still et al. 1979; Kussavsky et al. 1983). The dissociated effects on the anion and cation seen in the present study are consistent with both conclusions, although in the one previous report where both electrolytes were measured no effect was observed (Mischler et al. 1986). The initial rise and subsequent fall of sweat $\mathrm{Na}^{+}$suggested it is directly related to the changes in fatty acid status and not to an indirect effect of the marked change in cholesterol and triacylglycerol levels, which, in plasma at least, fell for the first 6 months before beginning to revert to baseline values. However, the cholesterol content of erythrocyte membranes (which we did not measure) is known to have a marked effect on both active and passive $\mathrm{Na}^{+}$efflux ( $\mathrm{Ng} \&$ Hockaday, 1986) and similar effects might also occur in the sweat duct epithelium.

There is evidence that plasma non-esterified fatty acids may regulate human leucocyte $\mathrm{Na}^{+}$pump activity, with unsaturated fatty acids, including linoleic acid, having an inhibitory effect on ouabain-sensitive $\mathrm{Na}^{+}$efflux (Kroes \& Ostwald, 1971). It is conceivable that a similar inhibitory effect of increased circulating plasma levels of non-esterified 
linoleic acid might operate in the coil of the sweat glands, so that their primary secretory product would have a lowered $\mathrm{Na}^{+}$content which would still be reflected in the sweat $\mathrm{Na}^{+}$ after partial reabsorption in the duct.

Changes in $24 \mathrm{~h}$ urine PGM levels (Fig. 4) are in keeping with previous observations (Mischler et al. 1986) and show a shift in the balance between $\mathrm{PGE}_{2}$ and $\mathrm{PGF}_{2 \alpha}$ in the direction of $\mathrm{PGE}_{2}$. This reflects the increased availability of linoleic acid, deficiency of which tends to increase $\mathrm{PGF}_{2 \alpha}$ synthesis (Chase \& Dupont, 1978). Although this shift might be expected to decrease any tendency to broncho-constriction produced by $\mathrm{PGF}_{2 \alpha}$, no significant change in lung function was observed. Urinary $\mathrm{PGE}_{2} \mathrm{M}$ levels are significantly higher in CF than in child controls generally (Burns \& Dodge, 1982). It has been reported that in guinea-pig tracheal epithelium, desensitization of $\beta$-adrenergic receptors by repeated stimulation with isoproterenol is accompanied by increased $\mathrm{PGE}_{2}$ synthesis (Omini et al. 1983). Increased $\mathrm{PGE}_{2} \mathrm{M}$ excretion, and increased $\mathrm{PGE}_{2}$ synthesis, could, therefore, reflect further downgrading of $\beta$-adrenoceptor sensitivity and thus possibly account for the reduction in sweat $\mathrm{Na}^{+}$. However, the uncertainty about the $\mathrm{PGE}_{2} \mathrm{M}$ measurements at 12 months means that these observations should be interpreted cautiously. Circulating plasma $\mathrm{PGE}_{2}$ and $\mathrm{PGF}_{2 \alpha}$ values decreased proportionately during the trial. No measurements were made of the $\mathrm{PG}$ derivatives of $20: 3 n-6, \mathrm{PGE}_{1}$ and $\mathrm{PGF}_{1 \alpha}$, although the presence of $18: 3 n$ 6 in the supplement might be expected to increase their synthesis.

The increase in urinary creatinine occurred while plasma creatinine levels decreased (Table 5). Parents reported increased physical activity by the subjects while they were receiving EFA supplements, but we were unable to show any objective differences in their clinical state as measured by height, weight, skinfold thickness or lung function. No specific measurements of muscle bulk were made. The urinary excretion of creatinine is generally regarded as an indirect measurement of muscle mass, but it is possible that the increase in these subjects might indicate increased breakdown of muscle, reflecting the change in PG balance. $\mathrm{PGF}_{2 \alpha}$ stimulates ribosomal protein synthesis from amino acids and therefore tends to be anabolic, whereas $\mathrm{PGE}_{2}$, whose output was probably increased relative to $\mathrm{PGF}_{2 \alpha}$, increases lysosomal protein degradation to amino acids and therefore has catabolic properties (Reeds et al. 1987). Although the subjects maintained their pre-existing height and weight centiles, they may therefore have had an increased protein turnover during EFA supplementation.

Evening primrose oil was provided by Efamol Ltd, Woodbridge Meadows, Guildford, Surrey. The remaining costs of the project were supported by the Cystic Fibrosis Research Trust, to whom the authors express their thanks. They also wish to thank the subjects and their parents for their cooperation and patience throughout the study. Special thanks are due to Dr Chris Patterson, Department of Medical Statistics at Queen's University, Belfast, who performed the statistical analyses.

\section{REFERENCES}

Burns, G. B. \& Dodge, J. A. (1982). Elevated levels of 13,14-dihydro-15-ketoprostaglandin metabolites and essential fatty acid deficiency in CF and heterozygote subjects. In Proceedings of the 11th Annual Meeting of the European Working Group on Cystic Fibrosis, June 1982, Brussels, Belgium, p. 76 [D. Baran, editor]. Leuven, Belgium: ACCO.

Carlstedt-Duke, J., Bronnegard, M. \& Strandvik, B. (1986). Pathological regulation of arachidonic acid release in cystic fibrosis: the putative basic defect. Proceedings of the National Academy of Sciences, USA 83, $9202-9206$.

Chase, H. P., Cotton, E. K. \& Elliott, R. B. (1979). Intravenous linoleic acid supplementation in children with cystic fibrosis. Pediatrics 64, 207-213. 
Chase, H. P. \& Dupont, J. (1978). Abnormal levels of prostaglandins and fatty acids in blood of children with cystic fibrosis. Lancet ii, 236-238.

Christophe, A., Verdonk, G., Robberecht, E. \& Mahathanakhun, R. (1985). Effect of supplementing mediumchain triglycerides with linoleic acid-rich monoglycerides on severely disturbed serum lipid fatty acid patterns in patients with cystic fibrosis. Annals of Nutrition and Metabolism 29, 239-245.

Dixon, W. J., Brown, M. B., Engleman, L., Frane, J. W., Hill, M. A. \& Jennrich, R. I. (1983). BMDP Statistical Software. Berkeley: University of Calfornia Press.

Dodge, J. A., Hamdi, I. A., Burns, G. M. \& Yamashiro, Y. (1981). Toddler diarrhoea and prostaglandins. Archives of Disease in Childhood 56, 705-707.

Elliott, R. B. \& Robinson, P. G. (1975). Unusual clinical course in a child with cystic fibrosis treated with fat emulsion. Archives of Disease in Childhood 50, 76-78.

Folch, J., Lees, M. \& Soane Stanley, G. H. (1957). A simple method for isolation and purification of total lipides from animal tissues. Journal of Biological Chemistry 226, 447-509.

Friedman, Z., Seyberth, H., Frolich, J. \& Oates, J. (1980). Effects of dietary variation in linoleic acid content on the major urinary metabolites of the E prostaglandins (PGE-M) in infants. In Archives of Prostaglandin and Thromboxane Research, vol. 8, pp. 1799-1805 [B. Samuelson and P. W. Padetti, editors]. New York: Raven Press.

Gibson, L. E. \& Cooke, R. E. (1959). A test for concentration of electrolytes in sweat in cystic fibrosis of the pancreas utilizing pilocarbine by iontophoresis. Pediatrics 23, 545-549.

Haning, R. V., Kieliszek, F. X. \& Alferino, S. P. (1977). A radioimmunoassay for 13,14-dihydro-15ketoprostaglandin $F_{2}$ with chromatography and internal recovery standard. Prostaglandins 13, 455-477.

Hubbard V. S., Dunn, G. D. \& di Sant'Agnese, P. A. (1977). Abnormal fatty acid composition of plasma lipids in cystic fibrosis. A primary or secondary defect? Lancet ii, 1302-1304.

Kroes, J. \& Ostwald, R. (1971). Erythrocyte membranes - effect of increased cholesterol content on permeability. Biochimica et Biophysica Acta 249, 647-650.

Kussavsky, E., Strandvik, B. \& Troell, S. (1983). Prospective study of fatty acid supplementation over 3 years in patients with cystic fibrosis. Journal of Pediatric Gastroenterology and Nutrition 2, 434-438.

Lefkowith, J. B., Sprecher, H. \& Needleman, P. (1986). The role and manipulation of eicosanoids in essential fatty acid deficiency. Progress in Lipid Research 25, 111-118.

Lloyd-Still, J. D., Johnson, S. B. \& Holman, R. T. (1981). Essential fatty acid status in cystic fibrosis and the effects of safflower oil supplementation. American Journal of Clinical Nutrition 34, 1-7.

Lloyd-Still, J. D., Simon, S. H., Wessel, H. U. \& Gibson, L. E. (1979). Negative effects of oral fatty acid supplementation on sweat chloride in cystic fibrosis. Pediatrics 64, 50-52.

McKenna, M. C., Hubbard, V.S. \& Bieri, J. G. (1985). Linoleic acid absorption from lipid supplements in patients with cystic fibrosis with pancreatic insufficiency and in control subjects. Journal of Pediatric Gastroenterology and Nutrition 4, 45-51.

McPherson, M. A. \& Dormer, R. L. (1987). The molecular and biochemical basis of cystic fibrosis. Bioscience Reports 7, 167-185.

Mischler, E. H., Parrell, S. W., Farrell, P. M., Raynor, W. J. \& Leman, R. J. (1986). Correction of linoleic acid deficiency in cystic fibrosis. Pediatric Research 20, 3641.

Ng, L. L. \& Hockaday, T. R. (1986). Non-esterified fatty acids may regulate human leucocyte sodium pump activity. Clinical Science, 71, 737-742.

Omini, C., Folco, G. C., Galli, G., Vigano, T.\& Berti, F. (1983). Desensitisation of $\beta$-adrenoceptor in guinea-pig trachea: a link with the prostaglandin system. Advances in Prostaglandin Thromboxane and Leukotriene Research 12, 161-166.

Parsons, H. G., O'Loughlin, E. V., Forbes, D., Cooper, D. \& Gall, D. G. (1988). Supplemental calories improve essential fatty acid deficiency in cystic fibrosis patients. Pediatric Research 24, 353-356.

Reeds, P. J., Palmer, R. M. \& Wahle, K. W. (1987). The role of metabolites of arachidonic acid in the physiology and pathology of muscle protein metabolism. Biochemical Society Transactions 15, 328-331.

Riordan, J. R., Rommens J. M., Kerem, B.-S., Alon, N., Rozmahel, R., Grzelczak, Z., Zielendski, J., Lok, S., Plavsic, N., Chou, J.-L., Drumm, M. L., Ianuzzi, M. C., Collins, F. S. \& Tsui, L.-C. (1989). Identification of the cystic fibrosis gene: cloning and characterisation of complementary DNA. Science 245, 1066-1073.

Rogiers, V., Dab, I., Michotte, Y., Vercruysse, A., Crokart, R. \& Vis, H. L. (1984). Abnormal fatty acid turnover in the phospholipids of the red blood cell membranes of cystic fibrosis patients (in vitro study). Pediatric Research 18, 704-709.

Rosenlund, M. L., Selekman, J. A., Kim, H. K. \& Kritchevsky, O. (1977). Dietary essential fatty acids in cystic fibrosis. Pediatrics 59, 428-432.

Senne, B. C. \& Mathias, M. M. (1987). Eiconsanoid release by isolated perfused lungs from guinea-pigs fed diets varying in linoleate. Federation Proceedings 46, 11690.

Winer, B. J. (1962). Statistical Principles in Experimental Design. New York: McGraw-Hill. 